\title{
Liquid crystalline polymer nanocomposites reinforced with in-situ reduced graphene oxide
}

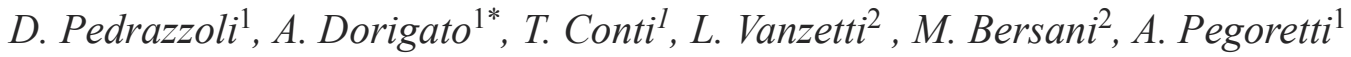 \\ ${ }^{1}$ University of Trento, Department of Industrial Engineering and INSTM Research Unit, Via Sommarive 9, 38123 Povo \\ (Trento), Italy \\ ${ }^{2}$ MiNALab Laboratory, Bruno Kessler Foundation, Via Sommarive 18, 38123 Povo (Trento), Italy
}

Received 1 December 2014; accepted in revised form 25 February 2015

\begin{abstract}
In this work liquid-crystalline polymer (LCP) nanocomposites reinforced with in-situ reduced graphene oxide are investigated. Graphene oxide (GO) was first synthesized by the Hummers method, and the kinetics of its thermal reduction was assessed. GO layers were then homogeneously dispersed in a thermotropic liquid crystalline polymer matrix (Vec$\operatorname{tran}^{\circledR}$ ), and an in-situ thermal reduction of GO into reduced graphene oxide (rGO) was performed. Even at low rGO amount, the resulting nanocomposites exhibited an enhancement of both the mechanical properties and the thermal stability. Improvements of the creep stability and of the thermo-mechanical behavior were also observed upon nanofiller incorporation. Furthermore, in-situ thermal reduction of the insulating GO into the more electrically conductive rGO led to an important surface resistivity decrease in the nanofilled samples.
\end{abstract}

Keywords: nanocomposites, mechanical properties, liquid-crystalline polymer

\section{Introduction}

Since its discovery in 2004, graphene, a one-atomthick planar sheet of $\mathrm{sp}^{2}$-bonded carbon atoms densely packed in a honeycomb crystal lattice, has generated intensive research activity in several areas of science and engineering due to its unique combination of superior mechanical, thermal and electrical properties $[1,2]$. Graphene is a very promising filler for the preparation of polymer nanocomposites, with enhanced mechanical [3, 4] and functional [5-9] properties. On the other hand, dispersion of graphene layers in a polymer matrix in still a difficult task [10]. Graphene oxide (GO) has recently attracted much attention due to its peculiar structure and properties which favor its dispersion in a wide variety of polymeric matrices, including polar polymers [11-13]. From a structural point of view, GO consists of a planar sheet of covalently bonded carbon atoms bearing various oxygen functional groups (e.g. hydroxyl, epoxide, and carbonyl groups) making it hydrophilic and easily dispersible in water as single sheets, to form stable colloidal suspensions [14-17]. Therefore the dispersion of GO in synthetic polymer matrices is an easier task since intercalated or fully exfoliated structures can be obtained [18-20]. GO can be reduced into graphene through chemical (e.g. by using hydrazine or hydrazine derivatives [21-23]) or thermal processes [24-27]. At the actual state of the art, the easiest way to produce bulk quantities of graphene is based on the reduction of GO [28-30]. Thermal reduction of GO has been reported to be very effective in restoring the graphene structure [31,32], but elevated temperatures (i.e. from 300 to $1000^{\circ} \mathrm{C}$ ) are usually required to achieve a complete $\mathrm{GO}$ reduction in a reasonable time. When thermally stable polymer matrices are

\footnotetext{
*Corresponding author, e-mail: andrea.dorigato@ing.unitn.it (C) BME-PT
} 
considered, an in-situ thermal reduction of GO nanoplatelets within the polymer matrix can be performed [24, 33, 34]. At this aim, a liquid crystalline polymer (LCP) matrix, known as Vectran ${ }^{\circledR}$, was chosen for the present research, because of its extremely high thermal stability and excellent mechanical properties [35].

In particular, thermotropic main chain LCP copolyesters represent a class of high-tech polymers which combine high mechanical performances with low density, resulting in outstanding specific properties [35-38]. Their typical applications include electronic devices, fiber optic coupling discs, automotive components, and sport equipment. Because the crystalline order between LCP polymer chains is maintained even at elevated temperatures, it is of great interest to determine how GO layers will disperse in LCP, and how the mechanical properties and electrical conductivity of the resulting materials will be modified. To the best of our knowledge, only limited studies are available on the effect of carbonaceous nanofillers on the physical and mechanical properties of LCPs [39-42].

Noteworthy, multifunctional materials such as LCP nanocomposites offer a great potential to enhance not only the mechanical and thermal properties with respect to the unmodified polymer, but also functional properties including high electrical and thermal conductivity, providing the opportunity to be used in different fields such as automotive, electronic packaging, aerospace, energy storage, etc. [43].

Therefore, the objective of this research is to prepare Vectran-based nanocomposites reinforced with in-situ thermally reduced graphene oxide, and to assess the effect played by filler incorporation on the thermal, mechanical and electrical properties of the resulting materials.

\section{Experimental part}

\subsection{Materials}

Commercially available Vectran ${ }^{\circledR}$ NT fibers having a linear density of 750 denier and 150 filaments/yarn and a circular cross-section with an average diameter of $25.5 \pm 2.1 \mu \mathrm{m}$ [38] were provided by Kuraray America Inc. (Fort Mill, USA). This special type of LCP is a thermotropic copolyester obtained by polycondensation of p-Hydroxybenzoic acid (HBA) and 6-hydroxy-2-naphthoic acid (HNA) in the molar ratio 73:27 (Figure 1). Graphite powder (particle size $<20 \mu \mathrm{m}$ ) was purchased from Sigma-Aldrich.

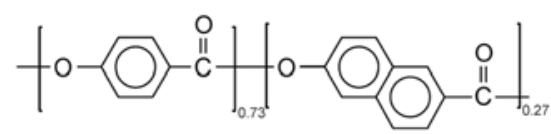

Figure 1. Chemical structure of Vectran $\mathrm{NT}^{\circledR}$ repeating unit

All other reagents with analytical grade purity were used without further treatments.

\subsection{Sample preparation}

GO was obtained from graphite powder by a modified Hummers method [44, 45]. GO powder was then dispersed in distilled water by sonication (Hielscher UP400S, 30 minutes) and centrifuged at $4000 \mathrm{rpm}$ for $15 \mathrm{~min}$ in order to remove unexfoliated graphite oxide and process residuals. A brownish homogenous suspension of GO with concentration up to $10 \mathrm{mg} / \mathrm{mL}$ was obtained.

Vectran fibers were first dried in a vacuum oven at $80^{\circ} \mathrm{C}$ for $1 \mathrm{~h}$. and then solved in a mixture $(70 / 30)$ of chloroform and pentafluorophenol. A solution with a polymer concentration of $1 \mathrm{wt} \%$ was obtained after stirring for $24 \mathrm{~h}$. GO was dispersed in chloroform by sonication for $30 \mathrm{~min}$ at a concentration lower than $1.2 \mathrm{mg} \cdot \mathrm{mL}^{-1}$ (as determined by thermogravimetric analysis). Vectran/GO solutions were then prepared by mixing the chloroform/GO suspension with a solution of Vectran fibers in chloroform/pentafluorophenol by stirring for $15 \mathrm{~min}$ and subsequent bath sonication (Elma Transsonic T460/H, Singen-Germany) for $15 \mathrm{~min}$. The solution was then cast and left at room temperature for $24 \mathrm{~h}$ to let the chloroform evaporate. Finally, the remaining solution was mixed with dichloromethane for $24 \mathrm{~h}$ at room temperature with subsequent drying in vacuum at $80^{\circ} \mathrm{C}$ for $24 \mathrm{~h}$. This final step was necessary to remove pentafluorophenol and chloroform residuals. In order to accomplish the in-situ thermal reduction of GO into reduced GO (rGO), a thermal treatment was performed on the Vectran nanocomposites in a vacuum oven (pressure of $25 \mathrm{mbar}$ ) at $290^{\circ} \mathrm{C}$ (heating rate of $1.5^{\circ} \mathrm{C} \cdot \mathrm{min}^{-1}$ ) for $4 \mathrm{~h}$. Thin films of Vectran nanocomposites were then obtained by a threestep thermoforming process by using a Carver hot press (Wabash, USA). Specifically, the material was first heated on a polytetrafluoroethylene mold at $320^{\circ} \mathrm{C}$ (heating rate of $5^{\circ} \mathrm{C} \cdot \mathrm{min}^{-1}$ ) and kept at this temperature for $5 \mathrm{~min}$. During the second step, forming of the nanocomposite films was performed by applying a pressure of $0.2 \mathrm{MPa}$ for $5 \mathrm{~min}$. The materials were then cooled down to $200^{\circ} \mathrm{C}$ at a cooling 
rate of $5^{\circ} \mathrm{C} \cdot \mathrm{min}^{-1}$ and were kept at this temperature for 15 minutes, in order to obtain a complete solidification of the material. After removing the applied pressure, a further annealing was performed at $290^{\circ} \mathrm{C}$ for $3.5 \mathrm{~h}$ (heating rate of $5^{\circ} \mathrm{C} \cdot \mathrm{min}^{-1}$ ), in order to relax the residual stresses accumulated during the compression molding stage and to favor a slow recrystallization of the samples [40]. In this way, nanocomposite films with thickness of about $250 \mu \mathrm{m}$ were produced with an rGO content of 1,3 and $5 \mathrm{wt} \%$. The unfilled matrix was denoted as VECTRAN, while nanocomposites were designated indicating the matrix and the filler amount. For instance, a sample filled with $5 \mathrm{wt} \%$ of rGO was indicated as VECTRAN_rGO5\%.

In order to investigate the kinetics of the filler reduction, neat GO films with a thickness of about $43 \mu \mathrm{m}$ were also obtained by casting a water/GO suspension and drying it at room temperature under vacuum for $24 \mathrm{~h}$. The resulting films were then thermally treated at various temperatures and for different times under vacuum at a heating rate of $1.5^{\circ} \mathrm{C} \cdot \mathrm{min}^{-1}$. Untreated GO was simply indicated as GO, while thermally treated samples were denoted indicating the treatment temperature and duration. For instance, GO_ $300^{\circ} \mathrm{C} \times 4 \mathrm{~h}$ denotes a $\mathrm{GO}$ film treated at $300^{\circ} \mathrm{C}$ for $4 \mathrm{~h}$.

\subsection{Experimental methodologies}

$\mathrm{X}$-ray diffraction (XRD) analyses were performed on the GO films by a Rigaku ${ }^{\circledR}$ 3D Max X-ray diffractometer (Kent, England) in Bragg-Brentano geometry operating at the $\mathrm{Cu} \mathrm{K} \alpha_{1}$ wavelength $(0.154059 \mathrm{~nm})$, applying a voltage of $40 \mathrm{kV}$ and a current of $30 \mathrm{~mA}$. The samples were scanned in a $2 \theta$ range between 5 and $45^{\circ}$ at a $2 \theta$ step of $0.05^{\circ}$.

X-ray photoelectron spectroscopy (XPS) analyses were carried out on GO films by using a XPS ESCA 200 Scienta spectrometer (VG Scienta, Uppsala, Sweden), adopting a monochromatic AlK $\alpha$ radiation $(h v=1486.6 \mathrm{eV})$ with emission angle of $90^{\circ}$ and at a pressure of 10-10 mbar.

Electrical resistance was assessed under the fourpoint configuration according to ASTM D4496-04 standard, in order to evaluate the surface resistivity of untreated GO and rGO films thermally treated at $180,220,260$ and $300^{\circ} \mathrm{C}$ for $4 \mathrm{~h}$. Electrical measurements were carried out at room temperature and under vacuum applying a potential of $2 \mathrm{~V}$ by an electrical generator Isotech IPS 330DD (Champaign,
United States), while current and voltage were monitored through Isotech IDM67 multimeters. Surface resistivity measurements were also performed on Vectran/rGO nanocomposites in a two-point resistance configuration, by applying a voltage of $50 \mathrm{~V}$ through an electrometer Keithley 6517A (Cleveland, USA) and reading the resistance value after $60 \mathrm{~s}$.

Thermogravimetric analysis (TGA) measurements were carried out by a thermobalance TA Instruments Q5000 (Waters LLC, New Castle, USA) at a heating rate of $5^{\circ} \mathrm{C} \cdot \mathrm{min}^{-1}$ from 50 to $900^{\circ} \mathrm{C}$ under a nitrogen flow of $25 \mathrm{~mL} \cdot \mathrm{min}^{-1}$ on samples of about $5 \mathrm{mg}$. Cryogenic fracture surfaces of Vectran nanocomposites were observed at various magnifications by using a field emission-scanning electron microscope (FESEM) Zeiss Supra 40 (Berlin, Germany) at acceleration voltages between 1 and $1.5 \mathrm{kV}$. Before the observation, a thin gold coating was deposited on the surface of the samples in order to minimize electrostatic charging effects.

Uniaxial tensile tests were performed with an Instron ${ }^{\circledR} 4502$ (Norwood, USA) tensile machine, on rectangular specimens $25 \mathrm{~mm}$ long, $2.5 \mathrm{~mm}$ wide and $0.25 \mathrm{~mm}$ thick. Tests were carried out at a crosshead speed of $1 \mathrm{~mm} \cdot \mathrm{min}^{-1}$ and setting a gauge length of $10 \mathrm{~mm}$. At least five specimens were tested for each sample. According to ISO 527 standard, the elastic modulus was determined as a secant value between deformation levels of 0.05 and $0.25 \%$.

Creep tests were carried out in tensile mode on a dynamic mechanical analyzer (DMA) TA Instruments Q800 (Waters LLC, New Castle) at a constant stress $\left(\sigma_{0}\right)$ of $4 \mathrm{MPa}$ for $1 \mathrm{~h}$ at $30^{\circ} \mathrm{C}$. Rectangular specimens, $2 \mathrm{~mm}$ long, $2.5 \mathrm{~mm}$ wide and $0.25 \mathrm{~mm}$ thick, were tested at a gage length of $10.4 \mathrm{~mm}$. The same apparatus and testing configuration was also adopted to determine dynamic mechanical thermal analysis (DMTA) thermograms in a temperature range from -100 to $200^{\circ} \mathrm{C}$, at a heating rate of $3^{\circ} \mathrm{C} \cdot \mathrm{min}^{-1}$ and a test frequency of $1 \mathrm{~Hz}$.

\section{Results and discussion}

\subsection{Characterization of GO and rGO}

\subsubsection{X-ray diffraction analyses}

XRD spectra of graphite, untreated GO and rGO treated at 180 and $300^{\circ} \mathrm{C}$ for 4 hours are reported in Figure 2 along with fitting lines. Noteworthy, the GO sample reduced at $90^{\circ} \mathrm{C}$ for $4 \mathrm{~h}$ manifested an XRD spectrum (not reported for brevity) practically coincident with that of untested GO. Therefore, the sam- 

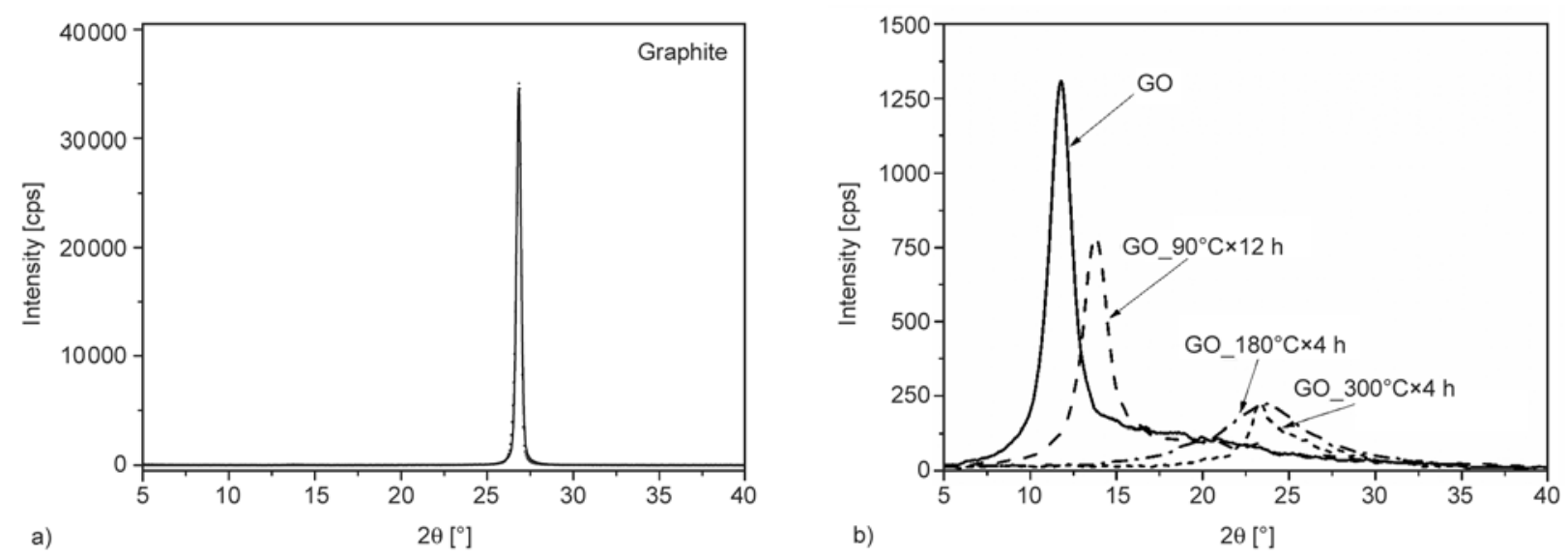

Figure 2. XRD spectra of graphite and of reduced graphene oxide: (a) graphite and (b) untreated GO, GO reduced for $4 \mathrm{~h}$ at 180 and $300^{\circ} \mathrm{C}$. Noteworthy, the GO sample reduced at $90^{\circ} \mathrm{C}$ was treated for $12 \mathrm{~h}$ in order to obtain a significantly different XRD spectrum.

Table 1. XRD parameters of pristine graphite, untreated GO and rGO samples

\begin{tabular}{|c|c|c|c|}
\hline Sample & $\begin{array}{c}\mathbf{d}_{002}{ }^{\mathrm{a}} \\
{[\AA]}\end{array}$ & $\begin{array}{c}\mathbf{D}_{\mathbf{0 0 2}}^{\mathbf{b}} \\
{[\AA]}\end{array}$ & $\begin{array}{c}\mathbf{N}_{\mathbf{G P}} \mathbf{c} \\
{[-]}\end{array}$ \\
\hline Graphite & 3.32 & 279.67 & 84.2 \\
\hline GO & 7.51 & 55.88 & 7.4 \\
\hline GO $90^{\circ} \mathrm{C} \times 4 \mathrm{~h}$ & 6.42 & 50.37 & 7.8 \\
\hline GO_ $180^{\circ} \mathrm{C} \times 4 \mathrm{~h}$ & 3.69 & 14.48 & 3.9 \\
\hline GO $300^{\circ} \mathrm{C} \times 4 \mathrm{~h}$ & 3.76 & 13.82 & 3.7 \\
\hline
\end{tabular}

${ }^{a}$ spacing between graphene layers.

bize of crystals formed by graphene layers.

${ }^{\mathrm{c}}$ Exfoliation degree, i.e. $D_{002} / d_{002}$.

ple was exposed at $90^{\circ} \mathrm{C}$ for a longer time $(12 \mathrm{~h})$ in order to obtain a significantly different XRD spectrum.

The diffractogram of graphite powder shows a strong peak at $2 \theta=26.5^{\circ}$ (Figure 2a) which correspond to the spacing between graphene layers (i.e. (022) crystal orientation [46]). Moreover, according to Bragg's law and Scherer's equation, the distance between the graphene layers $\left(d_{002}\right)$ and their size $\left(D_{002}\right)$ were determined to correspond to 3.32 and $279.67 \AA$, respectively (Table 1 ). In particular, the distance between the graphene layers is in good agreement with the value commonly reported in the literature (3.35 $\AA$ ), while the high value of NGP evidences an extended packing of graphene layers.

GO shows an intense peak at $2 \theta=11.7^{\circ}$ (Figure 2b), indicating a much larger interlamellar distance and crystal size when compared to pristine graphite. However, reduced GO samples manifest a less intense peak shifted towards higher values of $2 \theta$. In particular, the intensity and position of the peak are proportional to the temperature of treatment, indicating a progressive exfoliation of the GO occurring upon thermal treatment, as evidenced by the decreasing $N_{\mathrm{GP}}$ values. Moreover, the reduced $d_{002}$ observed for reduced GO samples can be attributed to the release of water molecules and loss of oxygen functional groups (i.e. epoxy, hydroxyl and carboxyl).

\subsubsection{X-ray photoelectron spectroscopy}

XPS chemical analyses were performed in order to evaluate the oxidation reduction level of films of both untreated GO and rGO thermally treated at various temperatures and annealing times. A survey and the $\mathrm{C}_{1 \mathrm{~s}}$ and $\mathrm{O}_{1 \mathrm{~s}}$ core levels were collected for each sample. In the used analytical conditions the sampling depth on these samples is around $10 \mathrm{~nm}$.

The core lines of $\mathrm{C}_{1 \mathrm{~s}}$ and $\mathrm{O}_{1 \mathrm{~s}}$ are reported in Figure 3, respectively. It is possible to observe that the carbon core level lineshape of untreated sample shows three well defined peaks. The peak at higher energy corresponds to $\mathrm{C}-\mathrm{C} / \mathrm{C}-\mathrm{H}$ bonds, the second peak, located around $287.2 \mathrm{eV}$, is related to $\mathrm{C}=\mathrm{O}$ bonds and it is the more intense peak in the untreated sample. A further peak $(\mathrm{C}-\mathrm{O}-\mathrm{O}-\mathrm{H})$ is also present at higher energy. In the annealed samples the $\mathrm{C}_{1 \mathrm{~s}}$ core level lineshapes present an evident modification. In fact for both reported samples the $\mathrm{C}-\mathrm{C} / \mathrm{C}-\mathrm{H}$ around a factor 3 and peak corresponding to oxidized carbon is strongly reduced. The thermal reduction is evident for both the samples but it is more pronounced when the annealing temperature is raised up to $300^{\circ} \mathrm{C}$. The $\mathrm{O}_{1 \mathrm{~s}}$ core level spectra point out the same behavior. Specifically, the untreated sample exhibits a single peak with a characteristic energy of $\mathrm{C}=\mathrm{O}$ bonds. With annealing it is possible to observe a strong intensity reduction and a peak enlargement proba- 

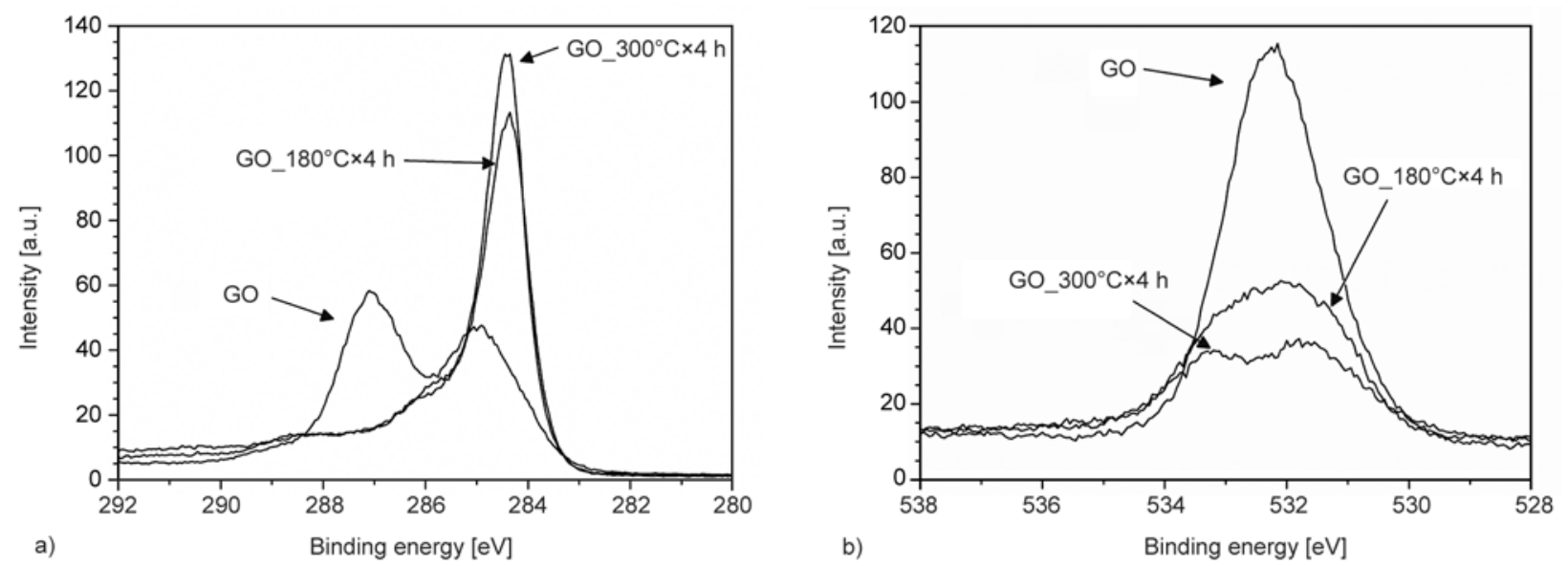

Figure 3. Comparison of core level (a) $\mathrm{C}_{1 \mathrm{~s}}$ peak and (b) $\mathrm{O}_{1 \mathrm{~s}}$ peak acquired during XPS analysis on untreated GO, GO reduced at 180 and $300^{\circ} \mathrm{C}$ for $4 \mathrm{~h}$

Table 2. XPS parameters: oxygen (O) and carbon (C) content evaluated in untreated $\mathrm{GO}$ and $\mathrm{GO}$ reduced at 180 and $300^{\circ} \mathrm{C}$ for $4 \mathrm{~h}$

\begin{tabular}{|l|c|c|c|}
\hline \multicolumn{1}{|c|}{ Sample } & $\begin{array}{c}\text { O content } \\
{[\%]}\end{array}$ & $\begin{array}{c}\text { C content } \\
{[\%]}\end{array}$ & C:O ratio \\
\hline GO & 30.7 & 69.3 & $2.26: 1$ \\
\hline GO_ $180^{\circ} \mathrm{C} \times 4 \mathrm{~h}$ & 19.0 & 81.0 & $4.27: 1$ \\
\hline GO_300 ${ }^{\circ} \mathrm{C} \times 4 \mathrm{~h}$ & 13.6 & 86.4 & $6.35: 1$ \\
\hline
\end{tabular}

bly due to the formation of suboxide compound. An estimation of the surface elemental composition based on XPS atomic sensitivity factors is reported in Table 2. These data confirm the progressive thermal reduction of GO with also a remarkable difference between the annealed samples.

\subsubsection{Surface resistivity}

Surface resistivity measurements were performed both on untreated and thermally-treated GO films to evaluate the efficacy of the thermal reduction performed for $4 \mathrm{~h}$ at $180,220,260$ and $300^{\circ} \mathrm{C}$, and the main results are summarized in Table 3 . In accordance to the literature data [23,27], untreated GO is characterized by a relatively high surface resistivity (i.e. $\sim 10^{12} \Omega / \mathrm{sq}$ ). However, the resistivity decreases by more than ten orders of magnitude after a thermal treatment at $180^{\circ} \mathrm{C}$ for $4 \mathrm{~h}$ (Table 3), indicating

Table 3. Surface resistivity of untreated GO and GO reduced at different temperatures for $4 \mathrm{~h}$

\begin{tabular}{|l|l|}
\hline \multicolumn{1}{|c|}{ Sample } & $\begin{array}{c}\text { Surface resistivity } \\
{[\boldsymbol{\Omega} / \mathbf{s q l}}\end{array}$ \\
\hline $\mathrm{GO}$ & $2.33 \cdot 10^{12}$ \\
\hline $\mathrm{GO} \_180^{\circ} \mathrm{C} \times 4 \mathrm{~h}$ & $6.72 \cdot 10^{1}$ \\
\hline $\mathrm{GO} \_220^{\circ} \mathrm{C} \times 4 \mathrm{~h}$ & $5.64 \cdot 10^{1}$ \\
\hline $\mathrm{GO} \_260^{\circ} \mathrm{C} \times 4 \mathrm{~h}$ & $4.57 \cdot 10^{1}$ \\
\hline $\mathrm{GO} \_300^{\circ} \mathrm{C} \times 4 \mathrm{~h}$ & $3.40 \cdot 10^{1}$ \\
\hline
\end{tabular}

an effective removal of most of the oxidized functional groups which allows the material to re-establish the $\mathrm{sp}^{2}$ configuration and to increase its surface conductivity [24]. At higher treatment temperatures a further slight resistivity decrease down to $\sim 3.4 \cdot 10^{1} \Omega$ /sq can be observed.

\subsubsection{Thermogravimetric analysis}

The oxidation treatment of graphite introduced large amount of oxygenated moieties on lamellae surface, therefore the thermogravimetric curve of GO films (reported in Figure 4) is characterized by various degradative steps, each of them representing a specific event. A first step $\left(\mathrm{S}_{1}\right)$ occurring between 50 and $140^{\circ} \mathrm{C}$ is attributed to the release of moisture adsorbed on the GO surfaces. Moreover, a second step $\left(\mathrm{S}_{2}\right)$ observable in the temperature range of 140 to $200^{\circ} \mathrm{C}$ is characterized by the maximum degradation rate (total mass loss $\sim 25 \mathrm{wt} \%$ for neat GO), that indicates the loss of oxygen containing functional groups (i.e. epoxy, hydroxyl and carboxyl) upon reduction. A third step $\left(\mathrm{S}_{3}\right)$ can be detected between 200 and $300^{\circ} \mathrm{C}$, and can be attributed to the further loss of epoxide groups. Finally, the steps $\mathrm{S}_{4}$ and $\mathrm{S}_{5}$ occur in a temperature range of 300 to $560^{\circ} \mathrm{C}$ and 560 to $800^{\circ} \mathrm{C}$, respectively, and can be attributed to the further loss of hydroxyl, carboxyl and ketone groups [47]. The TGA curve relative to GO films treated at $90^{\circ} \mathrm{C}$ for $12 \mathrm{~h}$ shows a lower mass loss during the first step due to the partial moisture evaporation occurring during the thermal treatment. Moreover, GO films treated at 180 and $300^{\circ} \mathrm{C}$ for $4 \mathrm{~h}$ evidence a significantly lower mass loss taking place upon the reduction steps $S_{2}$ and $S_{3}$, concurrently with a reduced degradation rate, indicating that $\mathrm{GO}$ has been 


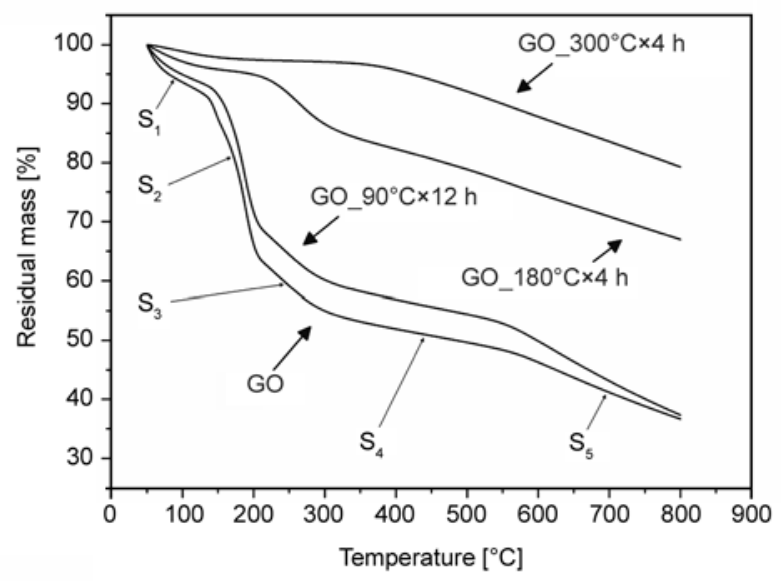

Figure 4. TGA curves of untreated GO, GO dried at $90^{\circ} \mathrm{C}$ for $12 \mathrm{~h}$ and $\mathrm{GO}$ reduced at 180 and $300^{\circ} \mathrm{C}$ for $4 \mathrm{~h}$ (nitrogen environment, heating rate $=5^{\circ} \mathrm{C} \cdot \mathrm{min}^{-1}$ )

reduced to a much higher extent during the previous thermal treatment. Therefore, the TGA analyses performed on GO films indicate that (i) the thermal reduction performed at temperatures as high as 180 and $300^{\circ} \mathrm{C}$ is able to reduce GO to a very high extent (as confirmed by the surface resistivity results presented earlier) and (ii) a thermal treatment performed on Vectran_rGO nanocomposites at around $300^{\circ} \mathrm{C}$ should be appropriate to greatly reduce $\mathrm{GO}$ and limit the matrix degradation.

\subsection{Characterization of Vectran/rGO nanocomposites}

\subsubsection{Microstructure}

SEM micrographs of the cryofractured surfaces of Vectran_rGO nanocomposites were acquired in order to assess the dispersion of GO lamellae achieved during the nanocomposite preparation. Figure 5a shows a micrograph of the unfilled matrix, evidencing the peculiar fibrillar morphology of Vectran [48, 49]. Because this morphology is preserved also when the nanofiller is present in the polymer matrix, the evaluation of the filler dispersion and distribution within the matrix is a rather difficult task for filler amount of $1 \mathrm{wt} \%$ (Figure $5 \mathrm{~b}$ ). However, micrometric-size structures with lamellar morphology can be recognized in the sample at filler loading of $5 \mathrm{wt} \%$ (Figure 5c), probably attributable to the adsorption of polymeric chains onto the planar filler surfaces.

\subsubsection{Thermal degradation behavior}

TGA analyses were performed in order to investigate the thermal degradation behavior both under inert and oxidative environment (nitrogen and air fluxes, respectively). According to the information reported

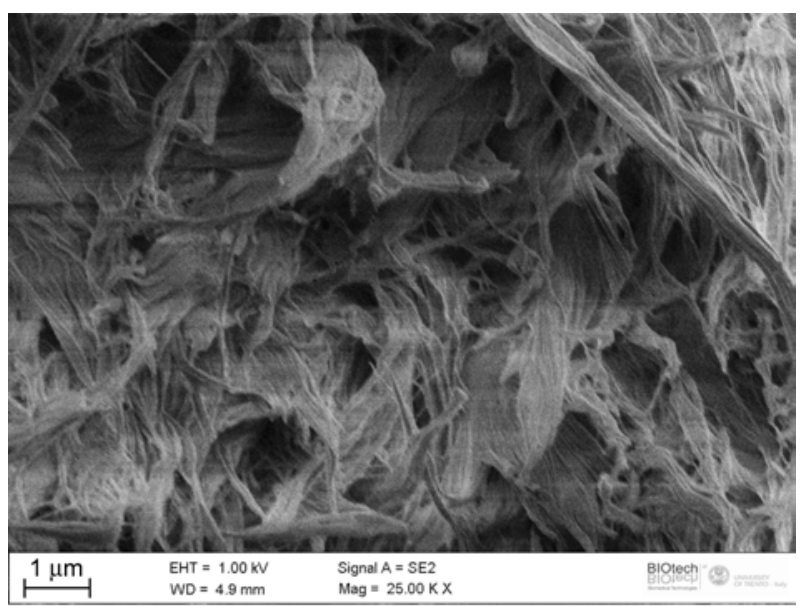

a)

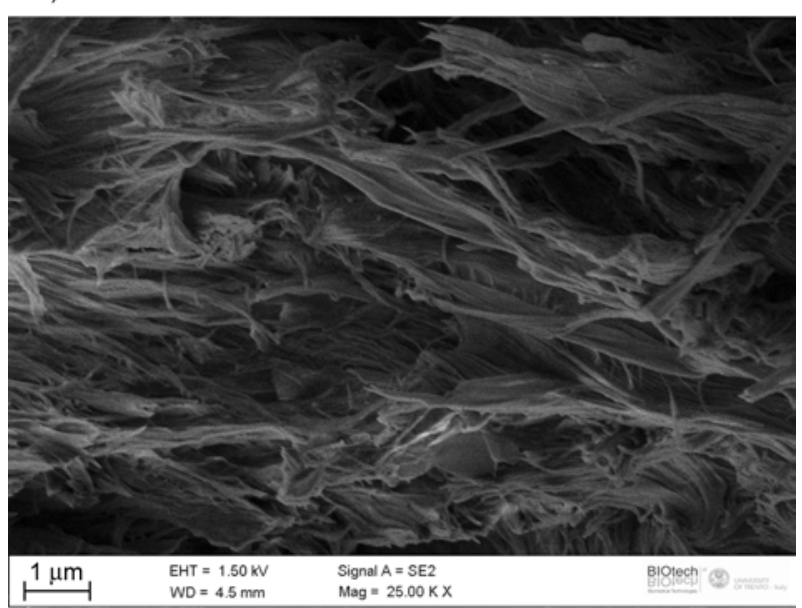

b)

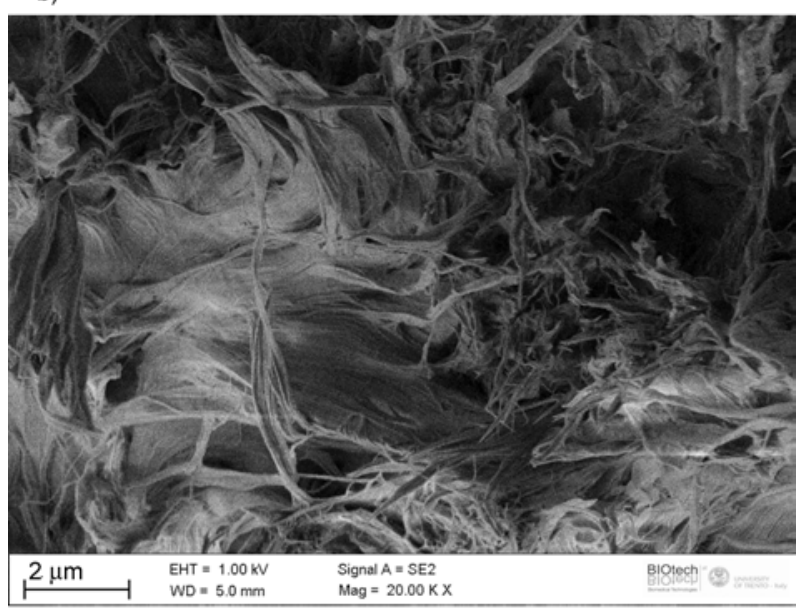

c)

Figure 5. SEM micrographs of cryofractured surfaces of VECTRAN (a) and Vectran/rGO nanocomposites with a filler amount of (b) $1 \mathrm{wt} \%$, (c) $5 \mathrm{wt} \%$

in the open scientific literature, the degradation products of Vectran mostly consist of $\mathrm{CO}_{2}$, while aromatic compounds are supposed to evolve more intensively starting from $460^{\circ} \mathrm{C}$. Finally, phenolic groups, aryl ester groups and ketone groups should be released above $500^{\circ} \mathrm{C}[50]$. TGA curves under inert environment (not reported for brevity) display a sin- 
Table 4. TGA results of Vectran and Vectran/rGO nanocomposites (nitrogen environment, heating rate $=$ $\left.5^{\circ} \mathrm{C} \cdot \mathrm{min}^{-1}\right)$

\begin{tabular}{|l|c|c|c|}
\hline \multicolumn{1}{|c|}{ Sample } & $\begin{array}{c}\mathbf{T}_{\mathbf{d}},{ }^{\circ}{ }^{\circ}{ }^{\mathbf{a}}{ }^{\mathbf{a}} \\
{\left[{ }^{\mathbf{C}]}\right.}\end{array}$ & $\begin{array}{c}\mathbf{T}_{\mathbf{d}, \mathbf{m a x}}{ }^{\mathbf{b}} \\
{\left[{ }^{\circ} \mathbf{C}\right]}\end{array}$ & $\begin{array}{c}\text { Residual mass } \\
{[\mathbf{\%}]}\end{array}$ \\
\hline VECTRAN & 489 & 501 & 38.5 \\
\hline VECTRAN_rGO1\% & 492 & 502 & 42.9 \\
\hline VECTRAN_rGO3\% & 499 & 505 & 44.0 \\
\hline VECTRAN_rGO5\% & 498 & 506 & 44.3 \\
\hline
\end{tabular}

${ }^{a}$ Onset degradation temperature.

${ }^{\mathrm{b}}$ Maximum degradation rate temperature.

gle degradation step occurring at temperatures higher than $450^{\circ} \mathrm{C}$, with a shift towards higher temperature for Vectran_rGO nanocomposites. As documented in Table 4, this shift corresponds to an increase of both the onset degradation temperature and the maximum degradation rate with the filler content. Therefore, filler incorporation results in a better thermal stability of the nanocomposites. In fact, exposure to elevated temperatures may cause the formation of filler agglomerates on the surface of the molten polymer, thus creating a protective barrier that may hinder the volatilization of molecular species formed during the thermal degradation process [51]. This could be also the reason why residual mass of nanofilled samples is higher than that of neat Vectran (see Table 4). Quite differently from TGA analyses conducted in inert environment, two main mass losses can be distinguished on TGA curves under oxidative conditions (Figure 6a), characterized by a distinct peak observable on the derivative mass plot (Figure 6b). The first degradation step occurring at temperatures over $475^{\circ} \mathrm{C}$ is mainly due to evolution of $\mathrm{CO}_{2}$, while the second degradation step recorded at temperatures above $525^{\circ} \mathrm{C}$ is characterized by the evolution of both $\mathrm{CO}_{2}$ and $\mathrm{CO}$ [50] until complete material's degradation, and no residual mass is recorded above $600^{\circ} \mathrm{C}$. Most importantly, not only the onset temperature but also the temperature of maximum degradation rate of both degradation steps significantly increased with the filler content, evidencing the beneficial effect of filler incorporation on the degradation behavior of the material. Noteworthy, the TGA analyses on Vectran and relative nanocomposites confirm that no significant degradation occurs during the process of $i n$-situ reduction of GO (as performed at $320^{\circ} \mathrm{C}$ for $5 \mathrm{~min}$ followed by annealing at $290^{\circ} \mathrm{C}$ for $3.5 \mathrm{~h}$, see Paragraph 2.2).

\subsubsection{Surface resistivity}

Neat Vectran exhibits very high surface resistivity value typical for an insulating polymer (i.e. $\sim 10^{13} \Omega / \mathrm{sq}$ ). Vectran_rGO composites show a remarkable decrease of the surface resistivity down to $3.7 \cdot 10^{7} \Omega /$ sq with a filler content of only $3 \mathrm{wt} \%$ (Table 5). Since the resistivity decreases less than one order of magnitude as the filler amount rises from 3 to $5 \mathrm{wt} \%$, a percolation threshold can be estimated between 1 and $3 \mathrm{wt} \%$. Therefore, resistivity data clearly evidence that GO reduction can effectively take place also in a solid polymer matrix at a relatively mild temperature. Specifically, the selected treatment temperature is supposed to be higher

Table 5. Surface resistivity of Vectran and Vectran/rGO nanocomposites

\begin{tabular}{|l|c|}
\hline \multicolumn{1}{|c|}{ Sample } & $\begin{array}{c}\text { Surface resistivity } \\
{[\mathbf{\Omega} / \mathbf{s q}]}\end{array}$ \\
\hline VECTRAN & $3.85 \cdot 10^{13}$ \\
\hline VECTRAN_rGO1\% & $2.40 \cdot 10^{13}$ \\
\hline VECTRAN_rGO3\% & $3.74 \cdot 10^{7}$ \\
\hline VECTRAN_rGO5\% & $2.09 \cdot 10^{7}$ \\
\hline
\end{tabular}

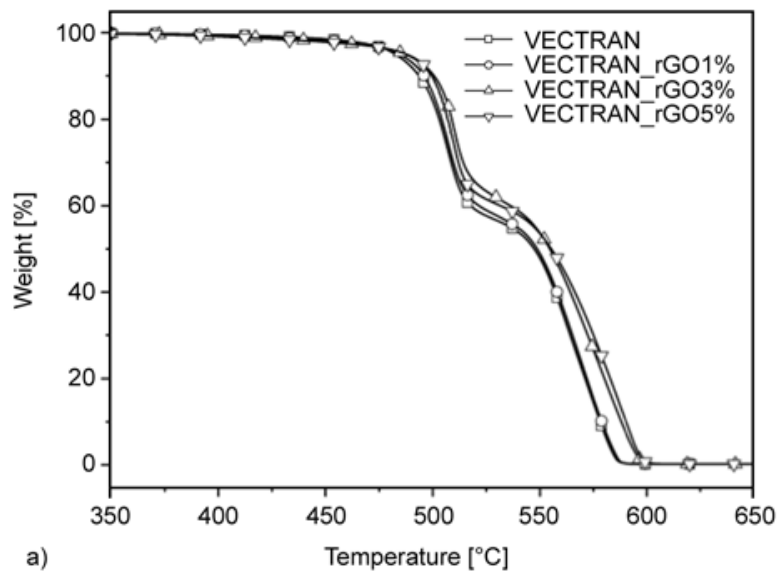

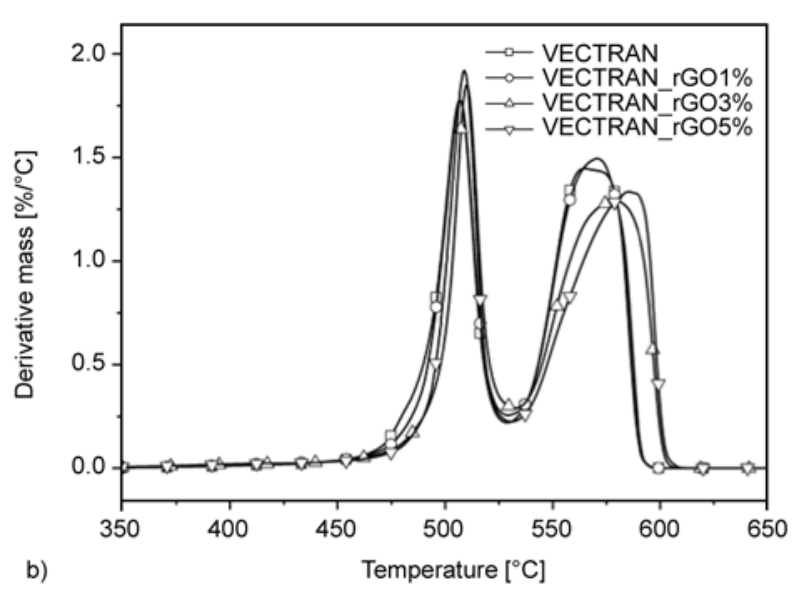

Figure 6. (a) TGA curves and (b) derivative TGA curves of VECTRAN and Vectran/rGO nanocomposites (air environment, heating rate $=5^{\circ} \mathrm{C} \mathrm{min}^{-1}$ ) 
enough to favor diffusive phenomena and the reaction kinetics. Concurrently, no significant matrix degradation occurs during treatment, as confirmed by TGA analyses.

\subsubsection{Mechanical response}

The typical stress-strain curves obtained under ramp tensile tests are reported in Figure 7, while the main parameters measurable from these tests are summarized in Table 6. The nanofiller induces an increase of the elastic modulus, with an improvement of $22 \%$ for the system filled with $1 \mathrm{wt} \%$ of GO compared to unfilled Vectran. The reinforcing effect provided by nanofiller incorporation could be explained by the reduction of macromolecules mobility constrained within filler agglomerates [52, 53]. Moreover, it has also been proved that the formation of a certain fraction of constrained matrix in proximity of the filler surfaces (i.e. interphase region) can significantly contribute to the stiffening effect [54]. Incorporation of a filler amount of $3 \mathrm{wt} \%$ results in further increase of the material stiffness. However, the progressive nanofiller agglomeration at elevated filler amounts leads to a decrease of the strain at break. On the other hand, the tensile strength does not seem to be appreciably affected by the presence of the nanofiller.

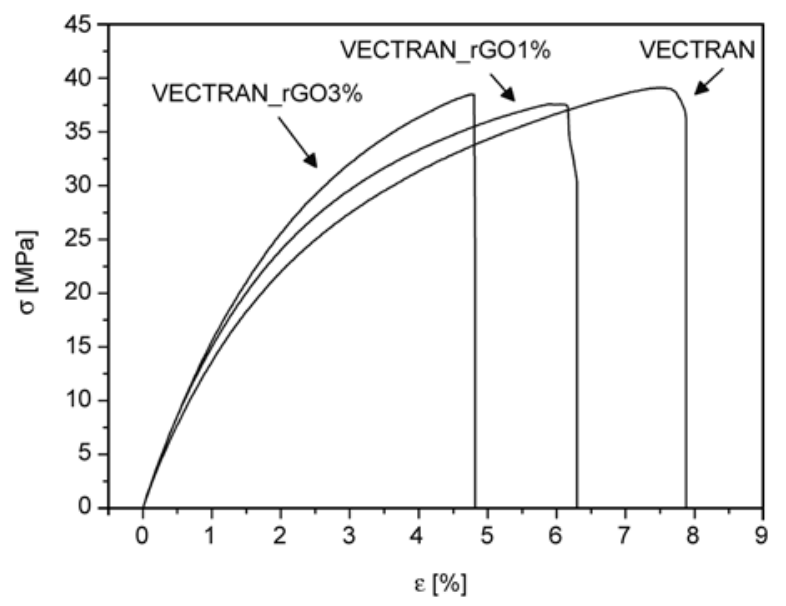

Figure 7. Stress/strain curves of VECTRAN and Vectran/ rGO nanocomposites

Table 6. Quasi-static tensile properties of Vectran and Vectran/rGO nanocomposites

\begin{tabular}{|l|c|c|c|}
\hline \multicolumn{1}{|c|}{ Sample* $^{*}$} & $\begin{array}{c}\text { Tensile } \\
\text { modulus } \\
{[\mathbf{M P a}]}\end{array}$ & $\begin{array}{c}\text { Tensile } \\
\text { strength } \\
{[\mathbf{M P a}]}\end{array}$ & $\begin{array}{c}\text { Strain at } \\
\text { break } \\
{[\%]}\end{array}$ \\
\hline VECTRAN & $1483 \pm 76$ & $42.7 \pm 3.9$ & $7.7 \pm 1.2$ \\
\hline VECTRAN_rGO1\% & $1805 \pm 50$ & $41.2 \pm 2.6$ & $6.4 \pm 1.7$ \\
\hline VECTRAN_rGO3\% & $1851 \pm 21$ & $40.2 \pm 3.7$ & $4.8 \pm 0.7$ \\
\hline
\end{tabular}

*The sample VECTRAN_rGO5\% was not tested due to problems with the specimens' preparation.

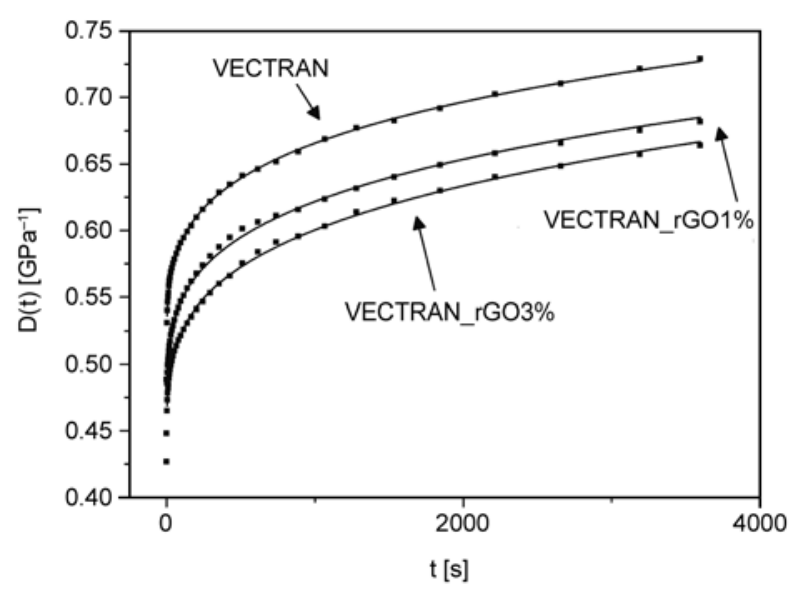

Figure 8. Creep compliance $(D(t))$ of VECTRAN and Vectran/rGO nanocomposites $\left(T=30^{\circ} \mathrm{C}, \sigma_{0}=4 \mathrm{MPa}\right)$. Experimental data were fitted applying the Findley model [55] (continuous lines).

In Figure 8 the isothermal $\left(30^{\circ} \mathrm{C}\right)$ creep compliance curves under a constant stress of $4 \mathrm{MPa}$ are reported for both unfilled Vectran and relative nanocomposites. Noteworthy, an accurate fit of the experimental data was achieved applying the Findley model [55] (continuous lines). According to these results, nanofiller incorporation results in an improved creep stability with respect to the neat Vectran. In particular, the elastic component of the creep compliance was significantly reduced, while only a slight effect can be noticed on the viscoelastic component.

A further investigation on the viscoelastic behavior of the prepared samples was carried out through DMTA analyses. The storage $\left(E^{\prime}\right)$ modulus increases with the filler loading (Figure 9a) over the whole range of testing temperatures. The enhancement of the thermo-mechanical properties upon nanofiller introduction can be explained considering three factors: the high intrinsic stiffness of the nanofiller, the good level of filler dispersion within the matrix and the degree of filler-matrix interfacial interaction [56]. However, while the first factor seems to have a significant impact on the stiffness of the prepared nanocomposites, the second factor was not properly investigated due to difficulties in the morphological analysis. The filler-matrix interfacial interactions can be further investigated by an accurate analysis of $\tan \delta$ plots. In particular, $\tan \delta$ plots show three distinct peaks attributed to the material's characteristic $\alpha, \beta$ and $\gamma$ relaxations (Figure $9 b$ ). The $\alpha$ relaxation is associated to the thermal relaxation of the whole polymeric chains corresponding to the glass transition temperature $\left(T_{\mathrm{g}}\right)$. In the specific case of LCP, this relaxation is attributed to the transition from 


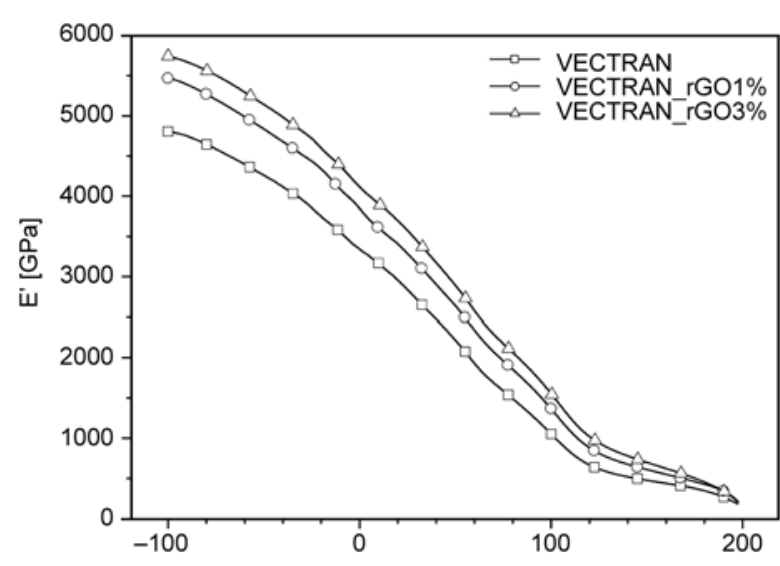

a)

$\mathrm{T}\left[{ }^{\circ} \mathrm{C}\right]$

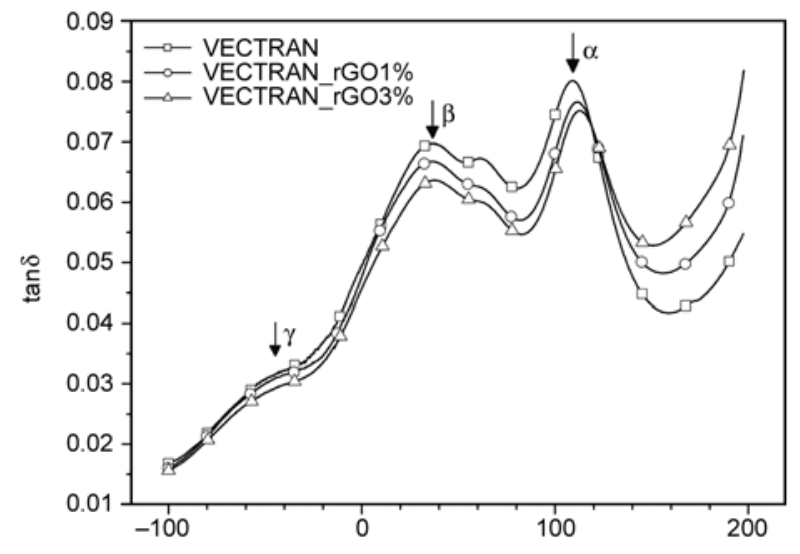

b)

$\mathrm{T}\left[{ }^{\circ} \mathrm{C}\right]$

Figure 9. DMA tests on VECTRAN and Vectran/rGO nanocomposites (frequency $=1 \mathrm{~Hz}$ ): (a) storage modulus $\left(E^{\prime}\right)$, (b) loss factor $(\tan \delta)$.

a quenched nematic phase to a thermally relaxed nematic phase. On the other hand, $\beta$ and $\gamma$ relaxations are associated to the $\mathrm{C}-\mathrm{O}$ chemical bonds distributed along the polymeric chains, specifically the rotation of naphthalene and phenylene rings, respectively [40]. The filler incorporation results in a slight increase of $T_{\mathrm{g}}$ (from 109 to $113^{\circ} \mathrm{C}$ for VECTRAN and VECTRAN_GO3\%, respectively), indicating a certain restriction of the segmental motion of the polymeric chains located in proximity of the filler's surfaces, while no clear change is observed on the $\beta$ and $\gamma$ relaxation temperatures. Therefore, taking into account that filler incorporation results in a limited $T_{\mathrm{g}}$ increase without any effect on the viscoelastic creep compliance, it can be hypothesized that the prepared materials are characterized by a relatively weak filler-matrix interaction degree. This conclusion can be explained considering that (i) the thickness of the physically absorbed Vectran layer on the surface of the filler surfaces is limited due to agglomeration and/or (ii) that the filler-matrix interfacial adhesion is restricted by the poor chemical affinity between the two phases. Both these aspects can affect the viscoelastic behavior of the resulting materials, and further efforts will be required in the future to reach a deeper comprehension of the obtained results.

\section{Conclusions}

New LCP nanocomposites reinforced with rGO were prepared by in situ thermal reduction of GO particles dispersed in a Vectran matrix. The kinetics of the GO thermal reduction was assessed by spectroscopic analyses (XRD and XPS), thermogravimetric analysis and surface resistivity measurements. It was found that a thermal treatment at $300^{\circ} \mathrm{C}$ for $4 \mathrm{~h}$ induced an extended reduction of GO nanoplatelets with an increase of the $\mathrm{C} / \mathrm{O}$ ratio content by a factor of 2.8. A decrease in resistivity (i.e. from $3.9 \cdot 10^{13}$ to $3.7 \cdot 10^{7} \Omega / \mathrm{sq}$ ) can be achieved at a filler amount of $3 \mathrm{wt} \%$. Improvements in the elastic modulus, creep stability and thermo-mechanical behavior were also related to nanofiller incorporation. Also the thermal degradation behavior was enhanced. On the other hand, the slight increase in the glass transition temperature in the nanomodified samples indicated that probably a poor filler dispersion was achieved.

\section{Acknowledgements}

The authors would like to thank Dr. Thiago Medeiros Araujo and Dr. Matteo Traina for their precious help on several aspects of the experimental work. The precious contribute of prof. Riccardo Ceccato in X-ray diffraction measurements is also kindly acknowledged.

\section{References}

[1] Geim A. K., Novoselov K. S.: The rise of graphene. Nature Materials, 6, 183-191 (2007).

DOI: $10.1038 /$ nmat1849

[2] Kuila T., Bose S., Mishra A. K., Khanra P., Kim N. H., Lee J. H.: Chemical functionalization of graphene and its applications. Progress in Materials Science, 57, 1061-1105 (2012).

DOI: $10.1016 /$ j.pmatsci.2012.03.002

[3] Kim H., Abdala A. A., Macosko C. W.: Graphene/polymer nanocomposites. Macromolecules, 43, 6515-6530 (2010). DOI: $10.1021 / \mathrm{ma100572 \textrm {e }}$

[4] Rafiee M. A., Rafiee J., Srivastava I., Wang Z., Song H., Yu Z-Z., Koratkar N.: Fracture and fatigue in graphene nanocomposites. Small, 6, 179-183 (2010). DOI: $\underline{10.1002 / \mathrm{smll} .200901480}$ 
[5] Kalaitzidou K., Fukushima H., Drzal L. T.: Multifunctional polypropylene composites produced by incorporation of exfoliated graphite nanoplatelets. Carbon, 45, 1446-1452 (2007).

DOI: $10.1016 /$ j.carbon.2007.03.029

[6] Tait M., Pegoretti A., Dorigato A., Kalaitzidou K.: The effect of filler type and content and the manufacturing process on the performance of multifunctional carbon/poly-lactide composites. Carbon, 49, 4280-4290 (2011).

DOI: $10.1016 /$ j.carbon.2011.06.009

[7] Ganguli S., Roy A. K., Anderson D. P.: Improved thermal conductivity for chemically functionalized exfoliated graphite/epoxy composites. Carbon, 46, 806-817 (2008).

DOI: $10.1016 /$ j.carbon.2008.02.008

[8] Hung M-T., Choi O., Ju Y. S., Hahn H. T.: Heat conduction in graphite-nanoplatelet-reinforced polymer nanocomposites. Applied Physics Letters, 89, 023117/1023117/3 (2006).

DOI: $10.1063 / 1.2221874$

[9] Wu H., Drzal L. T.: High thermally conductive graphite nanoplatelet/polyetherimide composite by precoating: Effect of percolation and particle size. Polymer Composites, 34, 2148-2153 (2013).

DOI: $10.1002 /$ Pc.22624

[10] Saravanan N., Rajasekar R., Mahalakshmi S., Sathishkumar T. P., Sasikumar K. S. K., Sahoo S.: Graphene and modified graphene-based polymer nanocomposites A review. Journal of Reinforced Plastics and Composites, 33, 1158-1180 (2014).

DOI: $10.1177 / 0731684414524847$

[11] Du X., Yu Z-Z., Dasari A., Ma J., Mo M., Meng Y., Mai Y-W.: New method to prepare graphite nanocomposites. Chemistry of Materials, 20, 2066-2068 (2008). DOI: $10.1021 / \mathrm{cm} 703285 \mathrm{~s}$

[12] Stankovich S., Piner R. D., Nguyen S. T., Ruoff R. S.: Synthesis and exfoliation of isocyanate-treated graphene oxide nanoplatelets. Carbon, 44, 3342-3347 (2006). DOI: 10.1016/j.carbon.2006.06.004

[13] Wang G., Wang B., Park J., Yang J., Shen X., Yao J.: Synthesis of enhanced hydrophilic and hydrophobic graphene oxide nanosheets by a solvothermal method. Carbon, 47, 68-72 (2009).

DOI: $10.1016 /$ j.carbon.2008.09.002

[14] Park S., An J., Jung I., Piner R. D., An S. J., Li X., Velamakanni A., Ruoff R. S.: Colloidal suspensions of highly reduced graphene oxide in a wide variety of organic solvents. Nano Letters, 9, 1593-1597 (2009). DOI: $10.1021 / \mathrm{nl} 803798 \mathrm{y}$

[15] Li D., Müller M. B., Gilje S., Kaner R. B., Wallace G. G.: Processable aqueous dispersions of graphene nanosheets. Nature Nanotechnology, 3, 101-105 (2008). DOI: $\underline{10.1038 / \text { nnano.2007.451 }}$
[16] Stankovich S., Piner R. D., Chen X., Wu N., Nguyen S. T., Ruoff R. S.: Stable aqueous dispersions of graphitic nanoplatelets via the reduction of exfoliated graphite oxide in the presence of poly(sodium 4-styrenesulfonate). Journal of Materials Chemistry, 16, 155-158 (2006).

DOI: 10.1039/B512799H

[17] Titelman G. I., Gelman V., Bron S., Khalfin R. L., Cohen Y., Bianco-Peled H.: Characteristics and microstructure of aqueous colloidal dispersions of graphite oxide. Carbon, 43, 641-649 (2005). DOI: $10.1016 /$ j.carbon.2004.10.035

[18] Cerezo F. T., Preston C. M. L., Shanks R. A.: Morphology, thermal stability, and mechanical behavior of [poly(propylene)-grafted maleic anhydride]-layered expanded graphite oxide composites. Macromolecular Materials and Engineering, 292, 155-168 (2007).

DOI: $10.1002 /$ mame.200600303

[19] Ying Z. R., Dang Z. M., Yan X. H., Ouyang X., Gao Y. Y.: Crystallization properties of polypropene/graphene oxide nanocomposites. Advanced Materials Research, 335-336, 347-350 (2011).

DOI: $10.4028 /$ www.scientific.net/AMR.335-336.347

[20] Wang J., Wang X., Xu C., Zhang M., Shang X.: Preparation of graphene/poly(vinyl alcohol) nanocomposites with enhanced mechanical properties and water resistance. Polymer International, 60, 816-822 (2011). DOI: $10.1002 /$ pi.3025

[21] Park S., An J., Potts J. R., Velamakanni A., Murali S., Ruoff R. S.: Hydrazine-reduction of graphite- and graphene oxide. Carbon, 49, 3019-3023 (2011).

DOI: 10.1016/j.carbon.2011.02.071

[22] Gilje S., Han S., Wang M., Wang K. L., Kaner R. B.: A chemical route to graphene for device applications. Nano Letters, 7, 3394-3398 (2007).

DOI: $10.1021 / \mathrm{n} 10717715$

[23] Ren P-G., Yan D-X., Ji X., Chen T., Li Z-M.: Temperature dependence of graphene oxide reduced by hydrazine hydrate. Nanotechnology, 22, 055705/1055705/8 (2011).

DOI: $\underline{10.1088 / 0957-4484 / 22 / 5 / 055705}$

[24] Traina M., Pegoretti A.: In situ reduction of graphene oxide dispersed in a polymer matrix. Journal of Nanoparticle Research, 14, 801/1-801/6 (2012). DOI: $10.1007 / \mathrm{s} 11051-012-0801-0$

[25] Jung I., Dikin D. A., Piner R. D., Ruoff R. S.: Tunable electrical conductivity of individual graphene oxide sheets reduced at 'low' temperatures. Nano Letters, 8, 4283-4287 (2008).

DOI: $10.1021 / \mathrm{n} 18019938$

[26] Chen W., Yan L., Bangal P. R.: Preparation of graphene by the rapid and mild thermal reduction of graphene oxide induced by microwaves. Carbon, 48, 1146-1152 (2010).

DOI: $10.1016 /$ j.carbon.2009.11.037 
[27] Kim C-J., Khan W., Park S-Y.: Structural evolution of graphite oxide during heat treatment. Chemical Physics Letters, 511, 110-115 (2011). DOI: $10.1016 /$ j.cplett.2011.06.016

[28] Sengupta R., Bhattacharya M., Bandyopadhyay S., Bhowmick A. K.: A review on the mechanical and electrical properties of graphite and modified graphite reinforced polymer composites. Progress in Polymer Science, 36, 638-670 (2011).

DOI: $10.1016 /$ j.progpolymsci.2010.11.003

[29] Cote L. J., Cruz-Silva R., Huang J.: Flash reduction and patterning of graphite oxide and its polymer composite. Journal of the American Chemical Society, 131, 11027-11032 (2009).

DOI: $10.1021 / \mathrm{ja} 902348 \mathrm{k}$

[30] Zhu Y., Murali S., Cai W., Li X., Suk J. W., Potts J. R., Ruoff R. S.: Graphene and graphene oxide: Synthesis, properties, and applications. Advanced Materials, 22, 3906-3924 (2010).

DOI: $10.1002 / \mathrm{adma} .201001068$

[31] Dai B., Fu L., Liao L., Liu N., Yan K., Chen Y., Liu Z.: High-quality single-layer graphene via reparative reduction of graphene oxide. Nano Research, 4, 434-439 (2011).

DOI: 10.1007/s12274-011-0099-8

[32] Yin K., Li H., Xia Y., Bi H., Sun J., Liu Z., Sun L.: Thermodynamic and kinetic analysis of low-temperature thermal reduction of graphene oxide. Nano-Micro Letters, 3, 51-55 (2011). DOI: 10.3786/nml.v3i1.p51-55

[33] Liu K., Chen L., Chen Y., Wu J., Zhang W., Chen F., Fu Q.: Preparation of polyester/reduced graphene oxide composites via in situ melt polycondensation and simultaneous thermo-reduction of graphene oxide. Journal of Materials Chemistry, 21, 8612-8617 (2011). DOI: $10.1039 / \mathrm{C} 1 \mathrm{JM} 10717 \mathrm{H}$

[34] Zhu Y., Stoller M. D., Cai W., Velamakanni A., Piner R. D., Chen D., Ruoff R. S.: Exfoliation of graphite oxide in propylene carbonate and thermal reduction of the resulting graphene oxide platelets. ACS Nano, 4, $1227-$ 1233 (2010).

DOI: $10.1021 / \mathrm{nn} 901689 \mathrm{k}$

[35] Pegoretti A., Traina M.: Liquid crystalline organic fibres and their mechanical behaviour. in 'Handbook of tensile properties of textile and technical fibres' (eds.: Bunsell A. R.) Woodhead Publishing, Cambridge, 354-436 (2009).

DOI: $10.1533 / 9781845696801.2 .354$

[36] Pegoretti A., Zanolli A., Migliaresi C.: Flexural and interlaminar mechanical properties of unidirectional liquid crystalline single-polymer composites. Composites Science and Technology, 66, 1953-1962 (2006). DOI: 10.1016/j.compscitech.2006.01.015

[37] Pegoretti A., Zanolli A., Migliaresi C.: Preparation and tensile mechanical properties of unidirectional liquid crystalline single-polymer composites. Composites Science and Technology, 66, 1970-1979 (2006).

DOI: $10.1016 /$ j.compscitech.2006.01.012
[38] Medeiros Araujo T., Pegoretti A.: Liquid crystalline single-polymer short-fibers composites. Composite Interfaces, 20, 287-298 (2013). DOI: $10.1080 / 15685543.2013 .796753$

[39] Biswas S., Fukushima H., Drzal L. T.: Mechanical and electrical property enhancement in exfoliated graphene nanoplatelet/liquid crystalline polymer nanocomposites. Composites Part A: Applied Science and Manufacturing, 42, 371-375 (2011).

DOI: 10.1016/j.compositesa.2010.12.006

[40] Kalfon-Cohen E., Pegoretti A., Marom G.: Annealing of drawn monofilaments of liquid crystalline polymer vectra/vapor grown carbon fiber nanocomposites. Polymer, 51, 1033-1041 (2010).

DOI: $10.1016 /$ j.polymer.2010.01.016

[41] Kim J. Y.: Carbon nanotube-reinforced thermotropic liquid crystal polymer nanocomposites. Materials, 2, 1955-1974 (2009).

DOI: $10.3390 / \mathrm{ma} 2041955$

[42] Qi B., Lu S. R., Xiao X. E., Pan L. L., Tan F. Z., Yu J. H.: Enhanced thermal and mechanical properties of epoxy composites by mixing thermotropic liquid crystalline epoxy grafted graphene oxide. Express Polymer Letters, 8, 467-479 (2014).

DOI: 10.3144 /expresspolymlett.2014.51

[43] Gibson R. F.: A review of recent research on mechanics of multifunctional composite materials and structures. Composite Structures, 92, 2793-2810 (2010). DOI: $10.1016 /$ j.compstruct.2010.05.003

[44] Hummers W. S. J., Offeman R. E.: Preparation of graphitic oxide. Journal of American Chemical Society, 80, 1339 (1958).

DOI: $10.1021 / \mathrm{ja} 01539 \mathrm{a} 017$

[45] Kovtyukhova N. I., Ollivier P. J., Martin B. R., Mallouk T. E., Chizhik S. A., Buzaneva E. V., Gorchinskiy A. D.: Layer-by-layer assembly of ultrathin composite films from micron-sized graphite oxide sheets and polycations. Chemistry of Materials, 11, 771-778 (1999). DOI: $10.1021 / \mathrm{cm} 981085 \mathrm{u}$

[46] Shang S., Zhao L., Liu W., Zhao P., Li X.: A highluminescence fringelike field emission from screenprinted carbon nanotube and zinc oxide composite film. Journal of Electromagnetic Analysis and Applications, 2, 649-653 (2010). DOI: $10.4236 /$ jemaa.2010.212085

[47] Huh S. H.: Thermal reduction of graphene oxide. in 'Physics and applications of graphene - Experiments', (ed.: Mikhailov S.) InTech, Rijeka, 73-90 (2011). DOI: $10.5772 / 14156$

[48] Sawyer L., Jaffe M.: The structure of thermotropic copolyesters. Journal of Materials Science, 21, 18971913 (1986).

DOI: $10.1007 / \mathrm{BF} 00547924$

[49] Weng T., Hiltner A., Baer E.: Hierarchical structure in a thermotropic liquid-crystalline copolyester. Journal of Materials Science, 21, 744-750 (1986). DOI: $10.1007 / \mathrm{BF} 01117348$ 
[50] Chung T. S.: Thermotropic liquid crystal polymers: Thin-film polymerization, characterization, blends, applications. Technomic Publishing, Lancaster (2001).

[51] Dorigato A., Pegoretti A., Frache A.: Thermal stability of high density polyethylene-fumed silica nanocomposites. Journal of Thermal Analysis and Calorimetry, 109, 863-873 (2012).

DOI: $10.1007 / \mathrm{s} 10973-012-2421-4$

[52] Dorigato A., Dzenis Y., Pegoretti A.: Filler aggregation as a reinforcement mechanism in polymer nanocomposites. Mechanics of Materials, 61, 79-90 (2013). DOI: 10.1016/j.mechmat.2013.02.004

[53] Dzenis Y. A.: Effect of aggregation of a dispersed rigid filler on the elastic characteristics of a polymer composite. Mechanics of Composite Materials, 22, 12-19 (1986).

DOI: $10.1007 / \mathrm{BF} 00606002$
[54] Karevan M., Kalaitzidou K.: Formation of a complex constrained region at the graphite nanoplatelets-polyamide 12 interface. Polymer, 54, 3691-3698 (2013). DOI: $10.1016 /$ j.polymer.2013.05.019

[55] Findley W. N., Lai J. S. Y., Onaran K.: Creep and relaxation of nonlinear viscoelastic materials: With an introduction to linear viscoelasticity. Dover, New York (1976).

[56] Jancar J.: Review of the role of the interphase in the control of composite performance on micro- and nanolength scales. Journal of Materials Science, 43, 67476757 (2008).

DOI: $10.1007 / \mathrm{s} 10853-008-2692-0$ 